\title{
Investigation of electronic and optical properties of wurtzite MgZnO using GGA + U formalism
}

\author{
R. Ibrahem, P. Narin, S. B. Lisesivdin \& E. Ozbay
}

To cite this article: R. Ibrahem, P. Narin, S. B. Lisesivdin \& E. Ozbay (2019) Investigation of electronic and optical properties of wurtzite $\mathrm{MgZnO}$ using GGA+U formalism, Philosophical Magazine Letters, 99:11, 424-433, DOI: 10.1080/09500839.2019.1696998

To link to this article: https://doi.org/10.1080/09500839.2019.1696998

曲 Published online: 04 Dec 2019.

Submit your article to this journal $\widetilde{T}$

Џ Article views: 41

Q View related articles ๘

View Crossmark data $\nearrow$ 


\title{
Investigation of electronic and optical properties of wurtzite MgZnO using GGA + U formalism
}

\author{
R. Ibrahem ${ }^{a}$, P. Narin ${ }^{a, b}$, S. B. Lisesivdin ${ }^{a}$ and E. Ozbay ${ }^{c, d, e}$

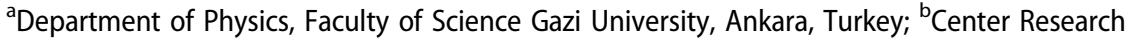 \\ Laboratory, Application and Research Center, Ankara Yıldırım Beyazıt University, Ankara, Turkey; \\ ${ }^{\mathrm{C}}$ Nanotechnology Research Center, Bilkent University, Ankara, Turkey; ${ }^{\mathrm{d} D e p a r t m e n t}$ of Physics, Bilkent \\ University, Ankara, Turkey; ${ }^{~}$ Department of Electrical and Electronics Engineering, Bilkent University, \\ Ankara, Turkey
}

\begin{abstract}
In this study, the electronic and optical properties of wurtzite $\mathrm{Mg}_{x} \mathrm{Zn}_{1-x} \mathrm{O}$ structures for different $\mathrm{Mg}$ mole fractions $(x)$ are studied using Density Functional Theory (DFT). In calculations, the generalised gradient approximation $(G G A+U)$ formalism is used with the Hubbard parameters $(U)$ are applied to $Z n-3 d$ and $0-2 p$ electrons of $\mathrm{ZnO}$. The calculated electronic band structures show that the band gap energies of the investigated structures increase linearly with increasing $\mathrm{Mg}$ mole fraction from 0 to $31.25 \%$ which is also quantitatively consistent with the previous experimental results. In addition, the electron effective masses of investigated $M_{x} Z_{n_{1-x}} \mathrm{O}$ structures are calculated. The electron effective masses of investigated structures show an increment linearly with increasing $\mathrm{Mg}$ mole fractions. The optical results show that the absorption edges of the structures move toward the higher energies region as the $\mathrm{Mg}$ mole fractions increase.
\end{abstract}

\section{ARTICLE HISTORY}

Received 19 March 2019

Accepted 13 November 2019

\section{KEYWORDS}

Electronic properties; optical properties; Density Functional Theory; magnesium zinc oxide; $\mathrm{GGA}+\mathrm{U}$

\section{Introduction}

II-VI semiconductors are one of the most important material groups that caused the technological revolution. Zinc oxide ( $\mathrm{ZnO})$, which is one of II-VI semiconductors took a good place from both experimental and theoretical investigations because of its electronic, optical and piezoelectric properties such as a direct and wide band gap $(3.37 \mathrm{eV})$, a large exciton binding energy $\sim 60 \mathrm{meV}$ at room temperature, a large piezoelectric coefficient, a strong luminescence, a high thermal conductivity, a high transparency in the visible region and radiation hardness [1-7].

When $\mathrm{ZnO}$ is alloyed with $\mathrm{MgO}$, an $\mathrm{Mg}_{x} \mathrm{Zn}_{1-x} \mathrm{O}$ structure can be obtained which has a stable wurtzite crystal structure up to $30-36 \%$ of $\mathrm{Mg}$ mole fraction, 
$\mathrm{Mg}_{x} \mathrm{Zn}_{1-x} \mathrm{O}$ material can be a useful semiconductor because it has a large band gap $(3.3-7.8 \mathrm{eV})[8,9]$. This alloy has unique electronic and optical properties and these properties make $\mathrm{Mg}_{x} \mathrm{Zn}_{1-x} \mathrm{O}$ a very suitable material for producing optoelectronic devices that are working at short wavelengths.

In recent decades, a lot of theoretical investigations that are relied on Density Functional Theory (DFT) had studied the electronic and optical properties of $\mathrm{ZnO}$ [10-12]. In these investigations, the local-density approximation (LDA) and generalised gradient approximation (GGA) functionalism have been used. It is known that the LDA and GGA functionals are insufficient to explain accurately the electronic properties of $\mathrm{ZnO}$ [13]. These functionals are underestimated the electronic band gap energy of $\mathrm{ZnO}$, misplaced the energy levels for the Zinc (Zn)-3d states and overestimated the crystal-field splitting energy [14].

In these formalisms, the strong hybridisation of localised $\mathrm{Zn}-3 \mathrm{~d}$ electrons with Oxygen $(\mathrm{O})-2 \mathrm{p}$ electrons are ignored. $\mathrm{Zn}-3 \mathrm{~d}$ electrons localise at very low binding energies that drive to strong hybridisation with an O-2p electron, this leads to a reduction of the band gap of $\mathrm{ZnO}$ [15]. This hybridisation is very important for the band gap formation in $\mathrm{ZnO}$, therefore the band gap of $\mathrm{ZnO}$ relies on the $\mathrm{Zn}-3 \mathrm{~d}$ and $\mathrm{O}-2 \mathrm{p}$ orbitals [16]. Recently, some of the theoretical investigations have studied the effects of Hubbard Parameters $(U)$ on p orbitals of $\mathrm{O}$ and $\mathrm{d}$ orbitals of transition metals [17-19]. As a result of that, the correction was applied to the $\mathrm{d}$ orbitals of $\mathrm{Zn}$ and $\mathrm{p}$ orbitals of $\mathrm{O}$ [20]. In these methods, where they are called as GGA $+U$ or $\mathrm{LDA}+U$, the orbital-dependent term has been added to the exchange-correlation potential.

In addition, there are few theoretical studies that relied on DFT shed light on the effect of $\mathrm{Mg}$ on the electrical and optical properties of $\mathrm{ZnO}$, in which the LDA and GGA functionals had been used to investigate the properties of wurtzite-MgZnO [21, 22]. The results showed the band gap linearly increased when the mole fraction of magnesium increased but the band gap values still have underestimation comparing with the experimental studies [8]. Few of theoretical studies have been used GGA + U to study Mg effects on wurtzite- $\mathrm{ZnO}$ properties and the results were very close to the experimental results [20].

In this work, the electronic and optical properties of wurtzite $\mathrm{Mg}_{x} \mathrm{Zn}_{1-x} \mathrm{O}$ for different $\mathrm{Mg}$ mole fractions (x) from $0 \%$ to $31.25 \%$ have studied using DFT where the geometry of the structure is optimised with an analytical potential and lattice parameters are taken from experimental literature. The calculations have performed using the GGA $+U$ formalism. The electronic band structures, the density of states (DOS), the electron effective masses and the absorption spectrum of studied $\mathrm{Mg}_{x} \mathrm{Zn}_{1-x} \mathrm{O}$ structures have calculated.

\section{Calculation method}

The calculations were performed using the Atomistix Toolkit-Virtual Nano Lab (ATK-VNL) software based on DFT. The calculations were carried out using 


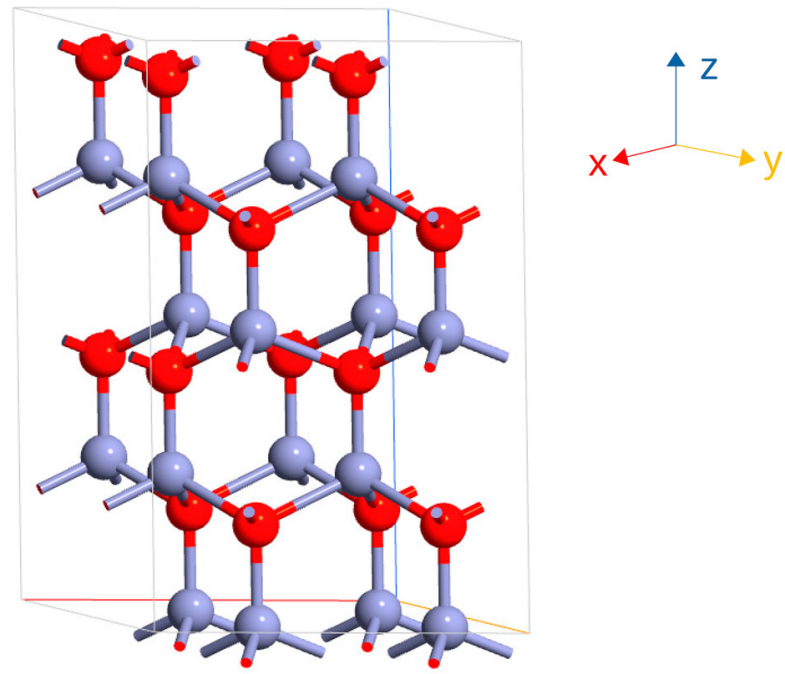

Figure 1. The crystal structure of the $2 \times 2 \times 2$ supercell of wurtzite- $\mathrm{ZnO}$, where the red and purple balls represent $O$ and $\mathrm{Zn}$ atoms, respectively.

GGA $+U$ functionalism. $U$ parameters were applied to $\mathrm{Zn}-3 \mathrm{~d}$ electrons and $\mathrm{O}-2 \mathrm{p}$ electrons of $\mathrm{Mg}_{x} \mathrm{Zn}_{1-x} \mathrm{O}$ to describe the on-site Coulomb corrections. The best $U$ parameters for $\mathrm{Zn}-3 \mathrm{~d}$ and $\mathrm{O}-2 \mathrm{p}$ orbitals of $\mathrm{Mg}_{x} \mathrm{Zn}_{1-x} \mathrm{O}$ were used as $U_{d}=10 \mathrm{eV}$ and $U_{p}=7 \mathrm{eV}$, respectively [23]. For $2 \times 2 \times 2$ super cell which has 32 atoms, the mesh cut-off energy and k-points were used as $500 \mathrm{eV}$ and $6 \times 6 \times 5$, respectively. Figure 1 shows the crystal structure of the $2 \times 2 \times 2$ supercell of the pure $\mathrm{ZnO}$. For each $\mathrm{Mg}_{x} \mathrm{Zn}_{1-x} \mathrm{O}$ structure, $\mathrm{Mg}$ positions were randomly inserted into $\mathrm{Zn}$ lattice points. Random Mg atom relocation is done for ten different random location choices and in every calculation results of electronic band structure show high similarity (i.e. bandgap values change between $1 \%$ and $2 \%$ with respect to each other). After building a randomly arranged $\mathrm{Mg}_{x} \mathrm{Zn}_{1-x} \mathrm{O}$ super cell, the structures were geometrically optimised under Perdone's analytic potential [24]. In geometric optimizations, the experimental lattice parameters of $\mathrm{Mg}_{x} \mathrm{Zn}_{1-x} \mathrm{O}$ crystal were used as $a=$ $b=0.32491+0.047 x \mathrm{~nm}$ and $c=0.52042-0.072 x \mathrm{~nm}$ [25]. The electronic and the optical calculations of $\mathrm{Mg}_{x} \mathrm{Zn}_{1-x} \mathrm{O}$ were performed for different mole fractions of $\operatorname{Mg}(0 \%, 6.25 \%, 12.5 \%, 18.75 \%, 25 \%$ and $31.25 \%)$, respectively.

\section{Results and discussion}

The electronic properties such as the electronic band structures, DOS and the electron effective masses for wurtzite $\mathrm{ZnO}$ and $\mathrm{Mg}_{x} \mathrm{Zn}_{1-x} \mathrm{O}$ with different $\mathrm{Mg}$ mole fractions have calculated. Figure 2 shows the conduction band minimum (CBM) and valance band maximum (VBM) values for the $\mathrm{ZnO}$ and $\mathrm{Mg}_{x} \mathrm{Zn}_{1-x} \mathrm{O}$ structures for different $\mathrm{Mg}$ mole fractions. Figure 3 shows the DOS of these structures. It is clear that the $\mathrm{Mg}_{x} \mathrm{Zn}_{1-x} \mathrm{O}$ structures have a wide direct band. The band gap of 


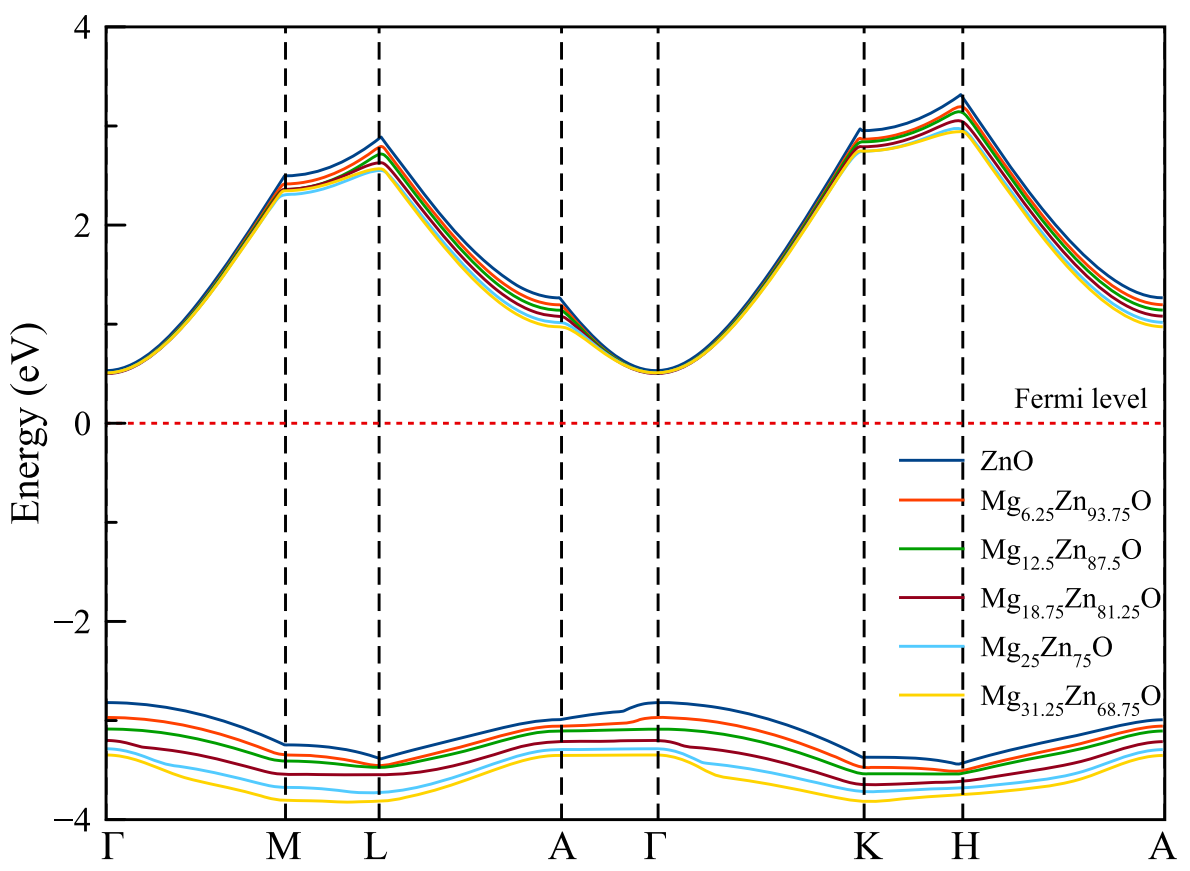

Figure 2. The CBM and VBM of wurtzite $\mathrm{Mg}_{x} Z \mathrm{n}_{1-x} \mathrm{O}$, for different $\mathrm{Mg}$ mole fractions (0-31.25)\%.

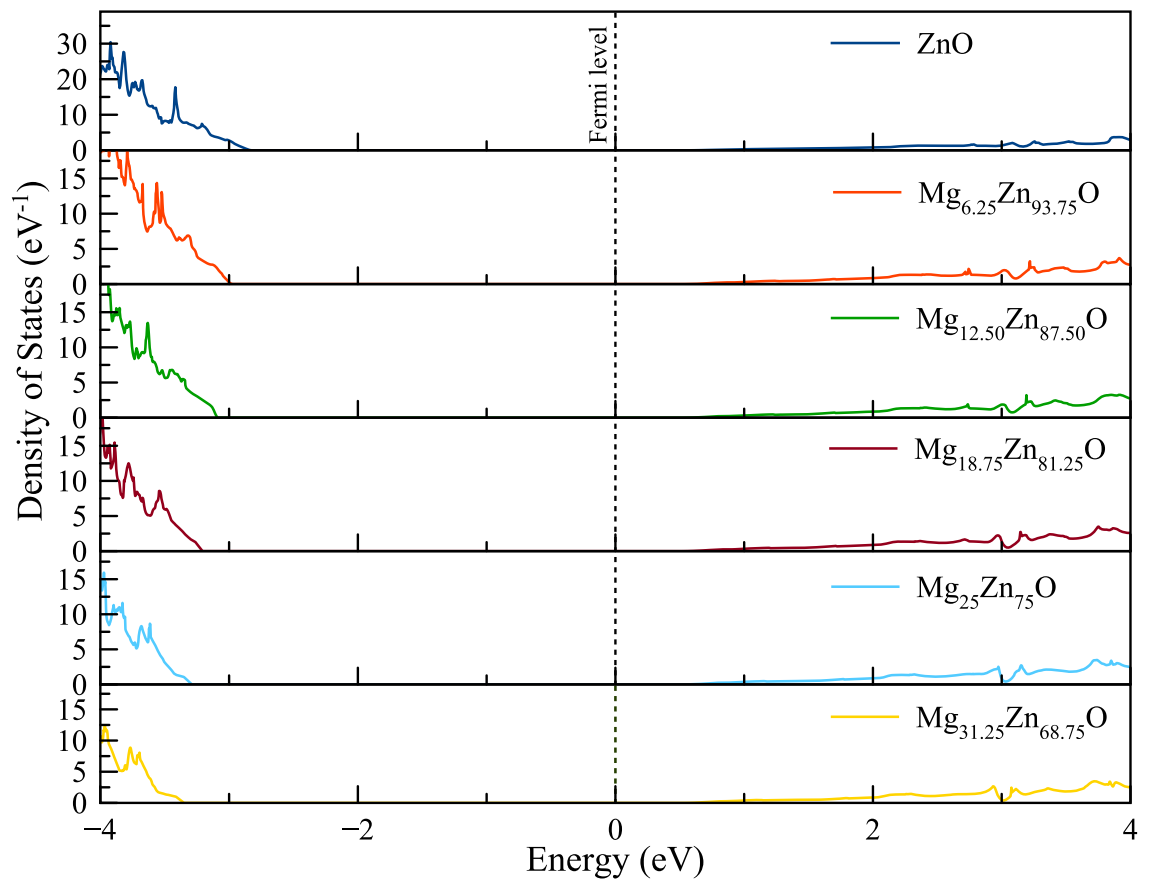

Figure 3. DOS of wurtzite $\mathrm{Mg}_{x} Z \mathrm{n}_{1-x} \mathrm{O}$, for different $\mathrm{Mg}$ mole fractions $0-31.25 \%$. 
Table 1. The calculated band gap energies, electron effective masses and static dielectric constants of wurtzite $\mathrm{ZnO}$ and $\mathrm{Mg}_{x} \mathrm{Zn}_{1-x} \mathrm{O}$ for different $\mathrm{Mg}$ mole fractions.

\begin{tabular}{lcccc}
\hline $\begin{array}{l}\text { Mg mole fraction } \\
\mathrm{x}(\%)\end{array}$ & $\begin{array}{c}\text { Band gap } \\
\text { energy }(\mathrm{eV})\end{array}$ & $\begin{array}{c}\text { Electron effective } \\
\text { mass }\left(m_{\mathrm{e}}{ }^{*}\right)\end{array}$ & $\begin{array}{c}\text { Static dielectric } \\
\text { constant } \varepsilon_{0}\end{array}$ & $\begin{array}{c}\text { High-frequency dielectric } \\
\text { constant } \varepsilon_{\infty}\end{array}$ \\
\hline 0 & 3.35 & 0.383 & 3.06 & 3.14 \\
6.25 & 3.48 & 0.390 & 3.01 & 2.80 \\
12.5 & 3.59 & 0.396 & 2.97 & 2.70 \\
18.75 & 3.70 & 0.404 & 2.92 & 3.23 \\
25 & 3.79 & 0.412 & 2.86 & 3.43 \\
31.25 & 3.86 & 0.416 & 2.81 & 3.74 \\
\hline
\end{tabular}

pure $\mathrm{ZnO}$ is $3.35 \mathrm{eV}$, which is very close to the experimental value of $\mathrm{ZnO}$ [26]. The obtained band gap values of wurtzite $\mathrm{Mg}_{x} \mathrm{Zn}_{1-x} \mathrm{O}$ with different $\mathrm{Mg}$ mole fractions are listed in Table 1. In order to compare the band gap energies of this study with other experimental band gap results of wurtzite $\mathrm{Mg}_{x} \mathrm{Zn}_{1-x} \mathrm{O}$, a comparison between the experimental and our results is shown in Figure 4. The calculated band gap energies of $\mathrm{Mg}_{x} \mathrm{Zn}_{1-x} \mathrm{O}$ show good consistency with the experimental results given in the literature [25,27-29].

The band gap values and the Mg mole fraction dependent behaviour show important similarity with the Ashrafi and Segawa's study [25], where the experimental lattice parameter's are taken. Because when $\mathrm{ZnO}$ is alloyed with $\mathrm{MgO}$, an $\mathrm{Mg}_{x} \mathrm{Zn}_{1-x} \mathrm{O}$ structure can be obtained which has a stable wurtzite crystal

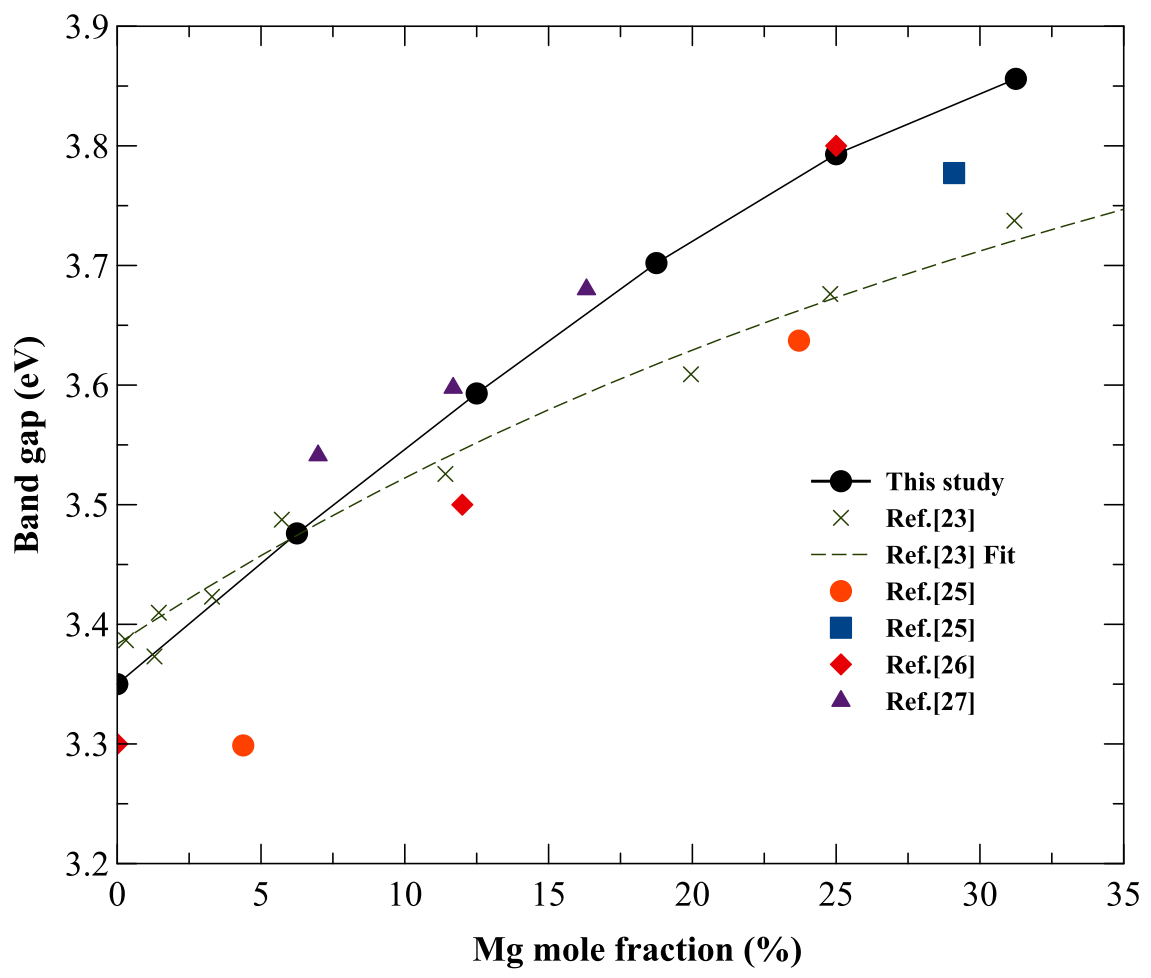

Figure 4. The calculated band gap values of $\mathrm{Mg}_{x} \mathrm{Zn}_{1-x} \mathrm{O}$ structures as a function of $\mathrm{Mg}$ mole fractions and the literature values. The solid line is drawn as a guide to the eye. 


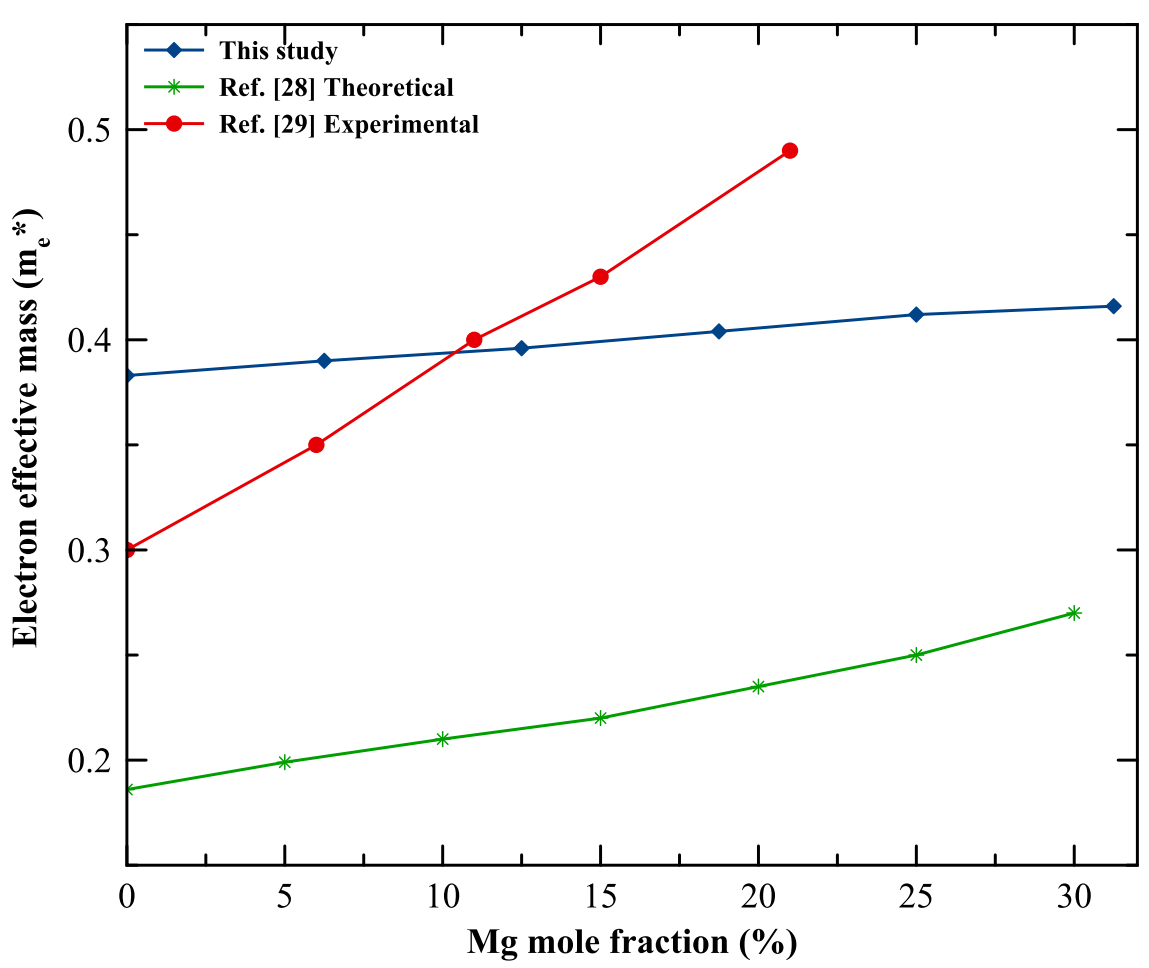

Figure 5. The calculated electron effective masses of wurtzite $\mathrm{Mg}_{x} \mathrm{Zn}_{1-x} \mathrm{O}$ as a function of $\mathrm{Mg}$ mole fractions and the literature values.

structure up to $30-36 \%$ of $\mathrm{Mg}$ mole fraction as pointed before. Further increase of the $\mathrm{Mg}$ composition resulted in the inclusion of rocksalt structure in the total structure. This situation was overcome by the use of a short-period $\mathrm{MgO} / \mathrm{ZnO}$ superlattice instead of the required wurtzite $\mathrm{MgZnO}$ alloy. This process is called quasi-ternary alloying [30]. However, it is out of the scope of this article, therefore upto 35\%, Mg mole fraction results are shown in Figure 4.

Figure 5 shows the electron effective masses of $\mathrm{Mg}_{x} \mathrm{Zn}_{1-x} \mathrm{O}$ structures as a function of the Mg mole fractions. The calculated electron effective masses of the studied structures increase linearly with increasing $\mathrm{Mg}$ mole fractions similar to the results found in the literature [31,32]. Although the effective mass values of this study are higher than other theoretical results and very close to the experimental results.

The static dielectric constants and the high-frequency dielectric constants of wurtzite $\mathrm{Mg}_{x} \mathrm{Zn}_{1-x} \mathrm{O}$ in the c-axis direction are calculated and listed in Table 1. The static dielectric constants decrease with the increasing $\mathrm{Mg}$ mole fractions. For the pure $\mathrm{ZnO}$, the experimental static dielectric constant value is found to be between 8.36 and 8.91 [33]. Our calculations underestimate the static dielectric constant values. $\mathrm{Ab}$ initio results of the static dielectric constant of $\mathrm{wz}-\mathrm{ZnO}$ are known to be underestimated with respect to the experimental results [34,35]. In this study, similar behaviour for the $\mathrm{wz}-\mathrm{MgZnO}$ is observed. The high-frequency dielectric constants of $\mathrm{Mg}_{x} \mathrm{Zn}_{1-x} \mathrm{O}$ are very consistent with the experimental results [36]. 

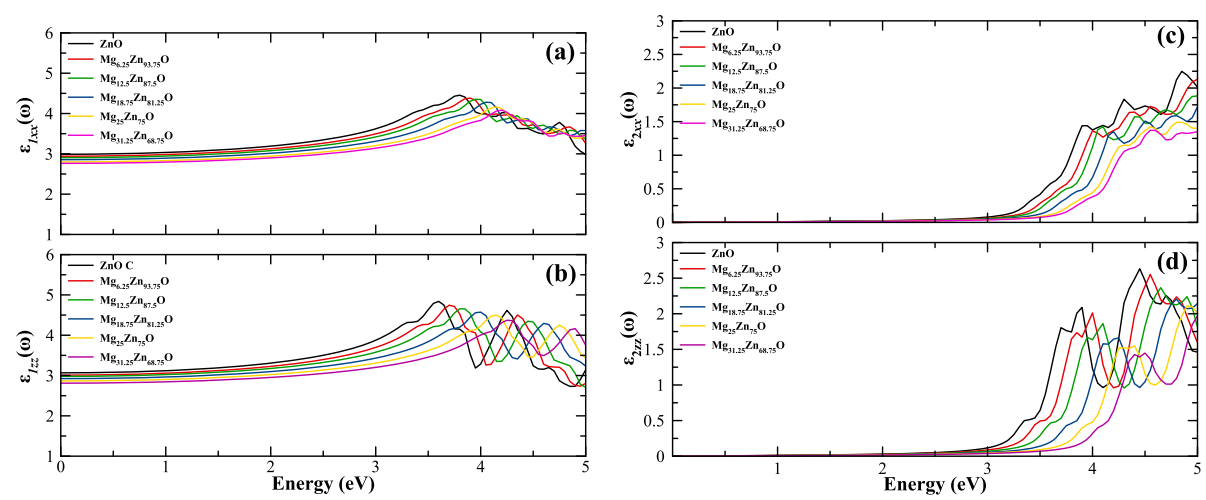

Figure 6. The real and the imaginary parts of the dielectric function of wurtzite $M g_{x} Z n_{1-x} O$ as a function of photon energy for (a) perpendicular direction to the $c$ axis $(E \perp c)$ and (b) parallel direction to the $c$ axis $(E \| c)$.

Figure 6 shows the real and the imaginary parts of the dielectric function for ( $\mathrm{a}$ and $\mathrm{c}$ ) perpendicular direction to the $\mathrm{c}$ axis $(E \perp c)$ and $(\mathrm{b}$ and $\mathrm{d}$ ) parallel direction to the $c$ axis $(E \| c)$ as a function of photon energy. The curves and the peaks move towards the higher energies (the lower wavelengths) as the $\mathrm{Mg}$ mole fraction increases.
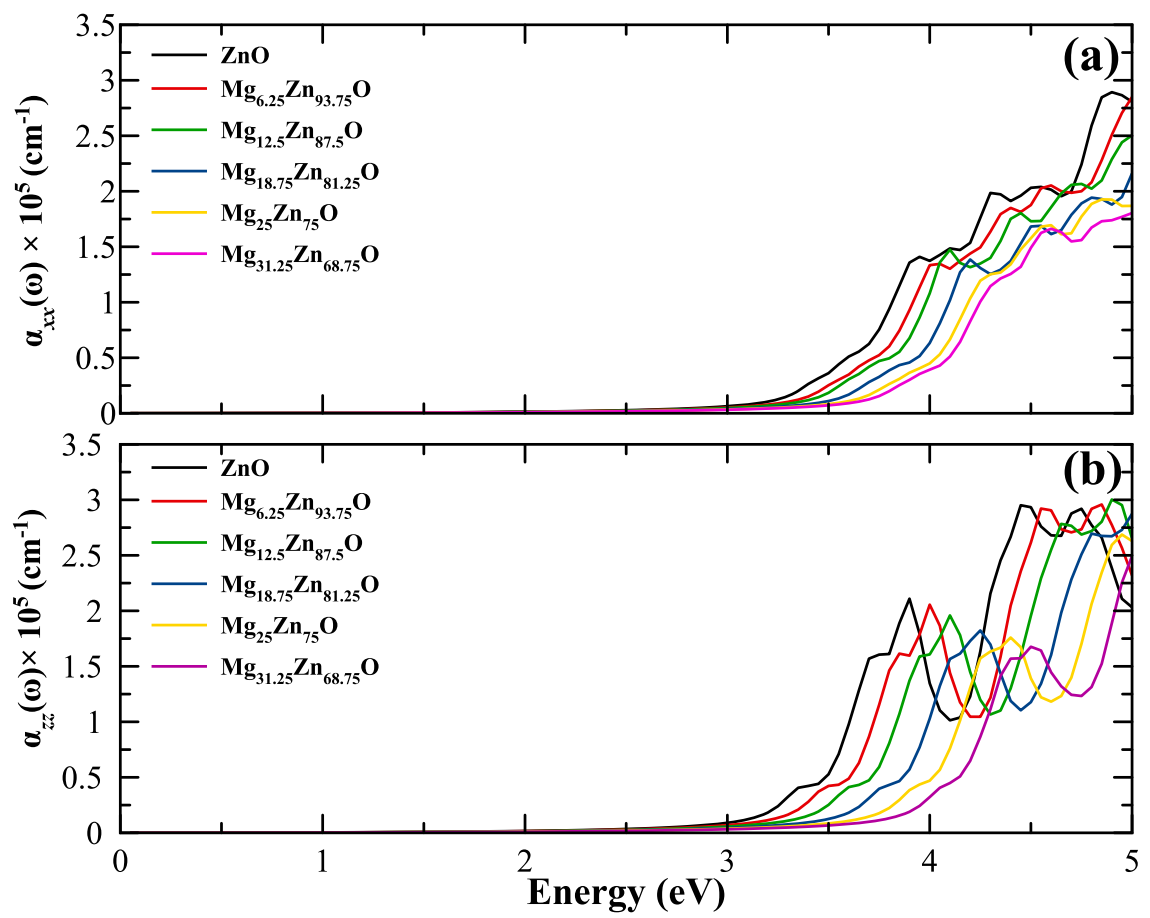

Figure 7. The absorption spectrum of wurtzite $\mathrm{Mg}_{x} \mathrm{Zn}_{1-x} \mathrm{O}$ as a function of photon energy for (a) perpendicular direction to the $c$ axis $(E \perp c)$ and (b) parallel direction to the $c$ axis $(E \| c)$. 


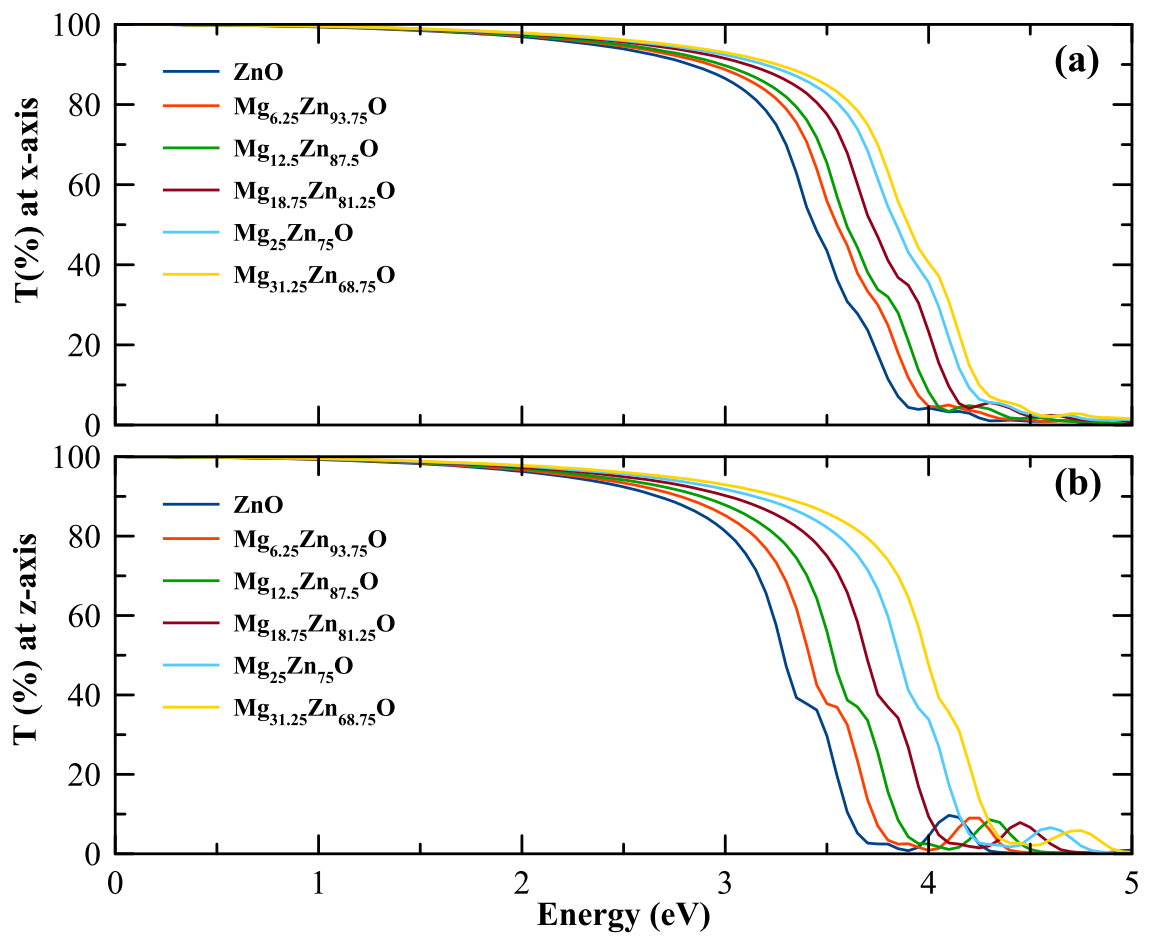

Figure 8. The transmittance spectrum of wurtzite $\mathrm{Mg}_{x} \mathrm{Zn}_{1-x} \mathrm{O}$ as a function of photon energy for (a) perpendicular direction to the $c$ axis $(E \perp c)$ and (b) parallel direction to the $c$ axis $(E \| c)$.

Figures 7 and 8 shows the absorption and transmittance spectrums of wurtzite $\mathrm{Mg}_{x} \mathrm{Zn}_{1-x} \mathrm{O}$ in (a) the perpendicular direction to the $\mathrm{c}$ axis $(E \perp c)$ and (b) in the parallel direction to the $c$ axis $(E|| c)$ as a function of the photon energies, respectively. It is clear that the absorption edges of the $\mathrm{Mg}_{x} \mathrm{Zn}_{1-x} \mathrm{O}$ shift towards the higher energies (i.e. towards the lower wavelengths) as the $\mathrm{Mg}$ mole fractions increase. Similar to the absorption spectrum, the transmittance spectrum of wurtzite $\mathrm{Mg}_{x} \mathrm{Zn}_{1-x} \mathrm{O}$ shifted to higher energy with increasing $\mathrm{Mg}$ mole fraction in the crystal. In addition, Figure 8 shows the anisotropic optical properties of wurtzite $\mathrm{Mg}_{x} \mathrm{Zn}_{1-x} \mathrm{O}$ due to the asymmetry in its crystal structure.

\section{Conclusion}

In this study, the electronic and the optical properties of wurtzite $\mathrm{Mg}_{x} \mathrm{Zn}_{1-x} \mathrm{O}$ for different Mg mole fractions have been calculated by DFT in which the electronic interactions are described within the GGA $+U$ formalism. The results show that the electronic band gap energy values of the $\mathrm{Mg}_{x} \mathrm{Zn}_{1-x} \mathrm{O}$ increase gradually with the increasing $\mathrm{Mg}$ mole fraction. The results are highly consistent with the experimental band gap results of wurtzite $\mathrm{Mg}_{x} \mathrm{Zn}_{1-x} \mathrm{O}$. In addition, the calculated electron effective masses of $\mathrm{Mg}_{x} \mathrm{Zn}_{1-x} \mathrm{O}$ shows a linear increase with increasing $\mathrm{Mg}$ mole fraction. The static dielectric constants decrease with the 
increasing $\mathrm{Mg}$ mole fractions. The high-frequency dielectric constants of $\mathrm{Mg}_{x} \mathrm{Zn}_{1-x} \mathrm{O}$ are very close to the experimental results in the literature. Furthermore, the absorption edges and the transmittance spectra of $\mathrm{Mg}_{x} \mathrm{Zn}_{1-x} \mathrm{O}$ structures are shifted to higher energy values with increasing $\mathrm{Mg}$ mole fraction as known in the literature. The results of this study showed that GGA + U formalism with analytical potential geometric optimisation and experimental lattice parameters usage had result in better accuracy in obtaining the correct electronic and optical properties of $\mathrm{ZnO}$ and $\mathrm{MgZnO}$. This method can be suggested to be used in other wide-bandgap oxide semiconductors, including $\mathrm{BeZnO}, \mathrm{CdZnO}$ and their quarternary compounds.

\section{Disclosure statement}

No potential conflict of interest was reported by the authors.

\section{Funding}

This work was supported by 'Turkish Scholarships Fund' and TUBITAK under Project No. 116F197. E.O. acknowledges partial support from the Turkish Academy of Sciences. S.B.L was supported in part by the Distinguished Young Scientist Award of Turkish Academy of Sciences [TUBA-GEBIP 2016].

\section{References}

[1] A. Mang and K. Reimann, Solid State Commun. 94 (1995) pp.251-254.

[2] D.C. Reynolds, D.C. Look and B. Jogai, Solid State Commun. 99 (1996) pp.873-875.

[3] D.M. Bagnall, Y.F. Chen, Z. Zhu, T. Yao, S. Koyama, M.Y. Shen and T. Goto, Appl. Phys. Lett. 70 (1997) pp.2230-2232.

[4] E. Andrade and M. Miki-Yoshida, Thin Solid Films 350 (1999) pp.192-202.

[5] S. Shionoya, W.M. Yen and H. Yamamoto, Phosphor Handbook, CRC Press, Boca Raton, 2018.

[6] D.I. Florescu, L.G. Mourokh, F.H. Pollak, D.C. Look, G. Cantwell and X. Li, J. Appl. Phys. 91 (2002) pp.890-892.

[7] F. Tuomisto, K. Saarinen, D.C. Look and G.C. Farlow, Phys. Rev. B 72 (2005) p.085206.

[8] J. Gao, G.J. Zhao, X.X. Liang and T.L. Song, J. Phys.: Conf. Ser. 574 (2015) p.012169. IOP Publishing.

[9] A. Ohtomo, M. Kawasaki, T. Koida, K. Masubuchi, H. Koinuma, Y. Sakurai and Y. Segawa, Appl. Phys. Lett. 72 (1998) pp.2466-2468.

[10] W. Kohn and L.J. Sham, Phys. Rev. 140 (1965) pp.A1133.

[11] J.P. Perdew, K. Burke and M. Ernzerhof, Phys. Rev. Lett. 77 (1996) pp.3865.

[12] G.S. Al Ghamdi and A.Z. Alzahrani, Phys. B. Condens. Matter. 407 (2012) pp.39753981.

[13] Y.B. Lv, Y. Dai, K. Yang, Z. Zhang, W. Wei, M. Guo and B. Huang, Phys. B. Condens. Matter. 406 (2011) pp.3926-3930.

[14] G.S. Alghamdi and A.Z. Alzahrani, Middle-East J. Sci. 13 (2013) pp.1144-1149.

[15] B.G. Zhai, L. Yang, Q.L. Ma and Y.M. Huang, Optoelectron. Mater. 1 (2015) pp.13-17. 
[16] Q. Liping, C. Changchun, Y. Yintang, Y. Xinhai and S. Chunlei, J. Semiconductors 35 (2014) pp.073004.

[17] A. Walsh, J.L. Da Silva and S.H. Wei, Phys. Rev. Lett. 100 (2008) pp.256401.

[18] X. Ma, B. Lu, D. Li, R. Shi, C. Pan and Y. Zhu, J. Phys. Chem. C 115 (2011) pp.46804687.

[19] R.M. Sheetz, I. Ponomareva, E. Richter, A.N. Andriotis and M. Menon, Phys. Rev. B 80 (2009) pp.195314.

[20] B. Li-Na, L. Jian-She and J. Qing, Chin. Phys. Lett. 28 (2011) pp.117101.

[21] A. Djelal, K. Chaibi, N. Tari, K. Zitouni and A. Kadri, Superlattices Microstruct. 109 (2017) pp.81-98.

[22] Y. Hu, B. Cai, Z. Hu, Y. Liu, S. Zhang and H. Zeng, Curr. Appl. Phys. 15 (2015) pp.423428.

[23] X. Ma, Y. Wu, Y. Lv and Y. Zhu, J. Phys. Chem. C. 117 (2013) pp.26029-26039.

[24] A. Pedone, G. Malavasi, M.C. Menziani, A.N. Cormack and U. Segre, J. Phys. Chem. B 110 (2006) pp.11780-11795.

[25] A.A. Ashrafi and Y. Segawa, Meas. Phenom. 23 (2005) pp.2030-2033.

[26] M. Minchev, S. Kitova and G. Danev, J. Optoelectron. Adv. M 11 (2009) pp.1312-1315.

[27] Y. Kamada, T. Kawaharamura, H. Nishinaka and S. Fujita, Jpn. J. Appl. Phys. 45 (2006) pp.L857.

[28] T. Takagi, H. Tanaka, S. Fujita and S. Fujita, Jpn. J. Appl. Phys. 42 (2003) pp.L401.

[29] H. Sheng, N.W. Emanetoglu, S. Muthukumar, S. Feng and Y. Lu, J. Electron. Mater. 31 (2002) pp.811-814.

[30] S. Fujita, H. Tanaka and S. Fujita, J. Cryst. Growth 278 (2005) pp.264-267.

[31] C. Franz, M. Giar, M. Heinemann, M. Czerner and C. Heiliger, MRS Online Proc. Library Arch. 1494 (2012) pp.57-63.

[32] J.G. Lu, S. Fujita, T. Kawaharamura, H. Nishinaka, Y. Kamada and T. Ohshima, Appl. Phys. Lett. 89 (2006) p.262107.

[33] N. Shkenov, B.N. Mbenkum, C. Bundesmann, V. Riede, M. Lorenz, D. Spemann and G. Wagner, J. Appl. Phys. 93 (2003) pp.126-133.

[34] H. I. Berrezoug, A. E. Merad, A. Zerga and Z. S. Hassoun, (2014, October). Ab-initio calculations of structural, electronic, and dielectric properties of ZnO. In 2014 North African Workshop on Dielectic Materials for Photovoltaic Systems (NAWDMPV) (pp. 1-5). IEEE.

[35] A. Schleife, C. Rödl, F. Fuchs, J. Furthmüller and F. Bechstedt, Phys. Rev. B 80 (2009) p.035112.

[36] C. Bundesmann, A. Rahm, M. Lorenz, M. Grundmann and M. Schubert, J. Appl. Phys. 99 (2006) p.113504. 